\title{
Behavioral consequences and intervention of financial shocks
}

Vance J. Larsen ${ }^{1 *}$, Riona Carriaga ${ }^{2 *}$, Hilary Wething ${ }^{3}$, Jiaying Zhao ${ }^{2,4 *}$, \& Crystal C. Hall ${ }^{1 *}$

${ }^{1}$ Evans School of Public Policy \& Governance, University of Washington

${ }^{2}$ Department of Psychology, University of British Columbia

${ }^{3}$ School of Public Policy, Pennsylvania State University

${ }^{4}$ Institute for Resources, Environment and Sustainability, University of British Columbia

(*shared first authors or senior authors)

Main text word count, including abstract, figures and tables: 7226/8000 words

Abstract word count: 187/200

Keywords count: 5

Please address correspondence to:

Jiaying Zhao

Department of Psychology

Institute for Resources, Environment and Sustainability

University of British Columbia

Vancouver, B.C., Canada, V6T 1Z4

Email: jiayingz@psych.ubc.ca 


\begin{abstract}
An increasing number of individuals report hardship to cover financial shortfalls, but most research to date examines expense shocks (e.g., a car repair) rather than income shocks (e.g., a one-time pay cut). Here we explore the behavioral consequences of expense and income shocks and propose a self-affirmation intervention to mitigate the psychological toll posed by financial shocks. In three experiments, participants were presented with a hypothetical financial emergency (i.e., a one-time income shock or expense shock) and answered questions afterwards. We found that income shocks evoked more methods of coping, were harder to cope with, more impactful on daily life, and perceived as more of a loss than expense shocks of the same amount. Self-affirmation as a behavioral intervention successfully mitigated some of the deleterious effects of the shocks. The findings contribute a more nuanced understanding of decision making in response to shortfalls by differentiating income and expense shocks. Our study suggests that there are psychological distinctions in how different financial shocks are perceived. This evidence can inform the strategies used to prevent and cope with financial emergencies and inform public policy to support household financial management.
\end{abstract}

Keywords: Decision making, mental accounting, self-affirmation, scarcity, policy 


\section{Introduction}

Financial emergencies are becoming increasingly pervasive. Since the COVID-19 pandemic, $62 \%$ of Americans are unable to cover an unexpected $\$ 1,000$ expense (Ostrowski, 2021), $63 \%$ have been living paycheck to paycheck (Berbaum, 2020), and $14 \%$ have wiped out their emergency savings (Pinkus, 2020). Even before the pandemic, only 43\% of Americans could cover an unexpected $\$ 2,000$ expense and only 49\% had emergency savings (Lin et al., 2019). To date, most financial resilience research has focused on expense shocks (e.g., a parking ticket) rather than income shocks (e.g., a decrease in wages or hours). As income shocks are increasingly prevalent in the U.S. labor market, the current study aims to fill this knowledge gap by addressing both income and expense shocks and exploring differences in mental accounting in terms of how people perceive and respond to these shocks. Moreover, we aim to test a selfaffirmation intervention that targets self-confidence to counteract any adverse psychological effects of financial shocks.

\section{Income Shocks and Volatility}

In recent decades, income shocks have become more prevalent due to new employment practices, including scheduling workers for many hours one week and few hours the next week to meet changing consumer demand, scheduling workers to work closing and opening shifts in succession, and requiring workers to remain on call throughout the week (Henly and Lambert, 2014; Lambert et al., 2019). These practices, which are often out of workers' control, can decrease the regularity and predictability of their work-time and earnings and increase workers' psychological distress (Schneider and Harknett, 2019). Consequently, this uncertainty forces families to manage negative income shocks in addition to occasional expense shocks (Morduch and Schneider, 2017). Income volatility is particularly concerning for workers earning low- 
wages who are, by definition, resource-constrained, and may lack the savings, assets, and access to credit that would insure against negative fluctuations in earnings.

Until recently, these types of employment practices were predominantly found in lowwage industries, such as retail and food services industries (Lambert et al., 2019). Beginning in March 2020, however, workers across the wage distribution experienced significant loss of income due to the COVID-19 pandemic. The pandemic has affected multiple industries and occupations including transportation, construction, food and beverages, and entertainment, causing workers to miss multiple paychecks (Bureau of Labor Statistics, 2020). It is estimated that during the first three quarters of 2020, nearly 500 million full-time jobs were lost worldwide due to workplace closures (International Labour Organization, 2020). The unexpected income loss forced many people to make difficult trade-offs between covering their rent and housing expenses and making payments on other bills such as credit cards and student loans. Much of the national dialogue during the pandemic has focused on whether, and how, families could cope with these unexpected income shortfalls. However, research in the asset building and financial services literature has primarily focused on people's ability to handle unexpected expense emergencies (Larrimore et al., 2017; Lin et al., 2016; Lusardi et al., 2011). Thus, the onset of the COVID-19 pandemic highlighted both how pervasive income shocks are and, relative to expense shocks, how little evidence exists on how people perceive and cope with these shocks.

This lack of evidence is particularly concerning as research has shown that financial shocks have deleterious effects on individuals' health and economic security (Alam and Mahal, 2014; Mendoza, 2009). Moreover, a large proportion of Americans lack sufficient emergency savings to draw upon when facing financial shocks (Bhargava and Lown, 2006; Bhutta and Detling, 2018; Lusardi et al., 2011). Households who set aside emergency savings (even small 
amounts) are less likely to experience financial hardship, specifically with regards to metrics such as food insecurity and utility disconnection (Gjertson, 2016). Since the COVID-19 pandemic, $52 \%$ of Americans said they have experienced negative financial impacts due to the pandemic (American Psychological Association, 2020), and 46\% of Canadians reported being stressed about financial troubles (Gadermann et al., 2021). Even prior to the pandemic, stress and anxiety about household finance has been prevalent, with over half of U.S. workers reporting being stressed by their financial position (Roll et al., 2016). This impact is even more pronounced for low- and moderate-income households, with some estimates indicating they are 10 times more likely to experience overwhelming financial stress, as compared to higher paid workers (Roll et al., 2016).

Common to studies examining how individuals cope with financial shocks is the focus on expense shocks, such as a car repair. In questions about expense shocks, respondents are considering the implications of an unexpected bill, expenditure, or other liability that would require cash or credit to address (The Federal Reserve, 2019). Less understood, however, are the implications of negative income shocks. Unpredictable work hours, and by extension income volatility, has been on the rise in recent years and when precarious work translates into volatility in workers' take-home pay, it can have consequences on people's psychological well-being and financial security (Henly and Lambert, 2014; D'Ambrosio et al., 2019; Lambert et al., 2019; Schneider and Harknett, 2019).

Distinguishing between these two types of shocks (i.e., income and expense shocks), and understanding differences in the coping abilities and strategies used by individuals, can shed light on how households manage their finances. Early evidence from the COVID-19 pandemic supports the notion that people cope with income shocks in distinct ways. A study of adults who 
lost their jobs during the pandemic reported that $46 \%$ of adults decreased their family spending on food, $58 \%$ put off major purchases, and $44 \%$ drew down savings or increased credit card debt (Karpman et al., 2020). To date, research on individual perceptions and coping mechanisms for these different types of shocks remains an unexamined area of research. To fill this gap, the current work examines the psychological responses to both income and expense shocks.

\section{Broad vs. Narrow Framing}

The theoretical motivation of the current study is that income shocks and expense shocks may trigger different framing of the shock. This impacts the perceived options, and difficulty, of coping with this type of financial emergency. Specifically, we predict that income shocks may trigger broad framing because the financial shortfall may be perceived as a drop in wealth, whereas expense shocks may trigger narrow framing because the shortfall is associated with a specific label (e.g., an unexpected bill or other expense). When people experience losses with specific financial labels, they tend to engage in narrow framing, defined as paying attention to narrowly defined losses within a specific mental financial account, compared to changes in their total wealth more broadly (Barberis and Huang, 2001). The different framing can cause people to engage in different mental accounting strategies to cope with the unexpected shock, affecting the mental accounts people draw upon to resolve the shortfall (Thaler, 1999). Specifically, we predict that the broad framing of income shocks may coincide with a more fungible view of money, leading people to explore more coping options, compared to the narrow framing of expense shocks. However, the broad framing of income shocks may also lead to a greater perceived difficulty of coping because the drop in wealth may be perceived as more of a loss than expense shocks of the same magnitude. Income shocks can be perceived as a greater loss than expense shocks of the same amount because the shortfall is less attributable to a specific 
cause while expense shocks often come with a reason (e.g., automobile repairs). Due to the greater perceived loss of income shocks, we predict that people are more willing to save for future emergencies after encountering an income shock than an expense shock of the same amount.

Past literature on mental accounting supports our predictions. For example, people were more likely to purchase a frivolous good with money that was won rather than earned, because the former was perceived as an unexpected windfall and the latter as income (O'Curry and Strahilevitz, 2001). Narrow framers tend to isolate each risk in decision-making under uncertainty, which can lead them to focus solely on current alternatives in decision making and ignore or neglect the long-term outcomes of other alternatives (Kahneman and Lovallo, 1993). Narrow framers are also less likely to be willing to increase their retirement savings contributions, and less willing to increase their monthly contributions to retirement plans (Shin et al., 2019). Narrow framing can impact the mental accounts people use to manage their household spending and budget - a process that seems to be more explicit for individuals with fewer

financial resources (Thaler, 1999; Heath and Soll, 1996). To date, many of the conclusions that have been drawn from this work have not accounted for the psychological component of how different types of shocks may be construed. The current study contributes a more nuanced look at these questions.

\section{Self-Affirmation and Financial Resilience}

To mitigate the psychological burdens of financial shocks, we propose that selfaffirmation can boost financial resilience to help people better cope with income and expense shocks. Self-affirmation theory suggests that individuals are motivated to maintain integrity to the self and to restore their self-image when their identity is under threat (Steele, 1988). When 
positive aspects of self-image are affirmed, this motivation enables individuals to respond less defensively in threatening situations (Sherman and Cohen, 2006). A previous study tested this

theory as an intervention to mitigate threats of poverty, where participants first underwent a selfaffirmation procedure (describing a personal experience where they felt successful and proud), and then completed cognitive tests and a behavioral measure of interest in public benefit programs. The study showed that self-affirmation not only improved cognitive functioning but also increased interests in benefit programs in low-income individuals (Hall et al., 2014). The study documented the first evidence that self-affirmation can increase the cognitive ability and receptivity to welfare services that may otherwise appear threatening. Building on past evidence, we predict that self-affirmation can increase financial resilience to shocks by mitigating the perceived coping difficulties of financial shocks and by improving self-confidence in handling future problems. Since we predict that income shocks are harder to cope with than expense shocks, we hypothesize that self-affirmation may have a larger beneficial impact for income shocks than expense shocks. This behavioral intervention has the potential to improve financial services and enrich financial resilience research.

\section{Current Study}

Our research design builds on the work of Lusardi et al. (2011) and other scholars who have examined the ability to handle financial shocks (Larrimore et al., 2017; Lin et al. 2016; Lusardi et al., 2011). Lusardi et al. (2011) explicitly state, that one limitation of their study was an inability to discern "whether respondents are thinking of a consumption shock" (aka, an expense shock) "or an income shock, which would have rather different consequences" (p. 6). Given the body of research regarding the psychological and behavioral concepts of mental 
accounting and more specifically narrow framing, we anticipate that individuals may view expense shocks and income shocks differently.

Across three experiments, we examine how income shocks and expense shocks influence coping abilities, impact on life, loss perception, and willingness to contribute to emergency savings. These behavioral consequences will be measured in randomized experiments that manipulate both the type of shock (income vs. expense) and the amount ( $\$ 400$ vs. $\$ 2,000$ ). Moreover, we aim to test a self-affirmation intervention that targets self-confidence to counteract any adverse psychological effects of financial shocks. In Experiment 1, we hypothesize that income shocks will be perceived as more difficult to cope with than expense shocks of the same amount. We also expect that individuals will perceive a need to rely on more methods to cope with income shocks relative to expense shocks. In Experiment 2 (pre-registered on osf.io/z864d), we hypothesize that income shocks and large shocks will lead to greater coping difficulty, a greater impact on daily lives, a greater perception of loss, and a greater willingness to contribute to emergency savings than expense shocks or smaller shocks. In Experiment 3 (pre-registered on osf.io/5c943), we will test a self-affirmation intervention to mitigate the psychological effects of both income and expense shocks. We predict that the intervention will reduce coping difficulty, impact on daily life, and perception of loss, and increase self-confidence and the willingness to contribute to emergency savings as compared to a control condition. Since we predict that income shocks are harder to cope with than expense shocks, we hypothesize that self-affirmation will have a larger beneficial impact for income shocks than expense shocks.

By disambiguating the different shock types and focusing attention on income shocks, the current work contributes new insights on how people respond to and manage unexpected financial shortfalls. Our findings can also provide important implications for scholars studying 
household finance, as well as policy professionals designing programs to help people cope with financial emergencies.

\section{Experiment 1}

\section{Participants}

We conducted an online study with Amazon Mechanical Turk workers. The data were collected in October and November of 2019, in two waves, to ensure there were no errors with implementation. Amazon Mechanical Turk provides a sample that is comparative to other survey methodologies and is more representative of the U.S. population than a convenience sample (Berinsky et al., 2012; Huff and Tingley, 2015). Of all data collected, we obtained 2,004 valid responses after excluding 196 observations because they were ineligible or had incomplete or invalid responses. A full description of participants demographics is presented in Table 1.

Table 1. Demographic and socioeconomic characteristics (percent breakdown) in Experiment 1.

\begin{tabular}{lr}
\multicolumn{2}{c}{ Income } \\
\hline Income & $n=2002$ \\
Less than 25K & 15.93 \\
$25 \mathrm{~K}-49 \mathrm{~K}$ & 29.72 \\
$50 \mathrm{~K}-74 \mathrm{~K}$ & 23.48 \\
$75 \mathrm{~K}-99 \mathrm{~K}$ & 14.69 \\
$100+\mathrm{K}$ & 16.18
\end{tabular}

\begin{tabular}{lr}
\multicolumn{2}{c}{ Gender } \\
\hline \\
Female & 57.604 \\
Male & 41.82 \\
Nonbinary & 0.2 \\
Missing/Entry Error/No Answer & 0.3
\end{tabular}

Race/Ethnicity
$\quad n=2002$

White

Black/African American

Asian

Hispanic/Latino

Multiple and/or Something Else

Age

\begin{tabular}{cr}
\multicolumn{2}{c}{ Age } \\
\hline & $n=2003$ \\
$18-24$ & 9.29 \\
$25-34$ & 37.99
\end{tabular}

75.4

7.4

6.6

5.6

4.9

37.99

\section{Education}

\begin{tabular}{lr}
\multicolumn{2}{c}{ Education } \\
\hline Did not Graduate HS & $n=2002$ \\
GED/HS Diploma & 0.6 \\
Some College & 10.09 \\
Associate's Degree & 22.78 \\
Bachelor's Degree & 11.79 \\
Master's/PHD Degree & 39.41 \\
& 15.34
\end{tabular}

\begin{tabular}{lr}
\multicolumn{2}{c}{ Marital Status } \\
\hline & $n=2004$ \\
Never married & 31.89 \\
Married & 46.86
\end{tabular}


In line with previous research using MTurk, the demographic and socioeconomic characteristics of our survey sample differed from those of the United States overall, but were significantly more representative than conventional samples of college undergraduates (Hitlin, 2016). Despite having above-average education and share of female participants, participants' racial identity and household income closely reflects national averages (United States Census Bureau, 2019).

\section{Stimuli and Procedure}

Participants were randomly assigned into one of four conditions: a small $(\$ 400)$ expense shock, a small $(\$ 400)$ income shock, a large $(\$ 2,000)$ expense shock, or a large $(\$ 2,000)$ income shock. Table S1 presents an analysis of balance of check across conditions. In each condition, participants were asked how confident they were in their ability to handle a specific type and size of financial shock, and rated their confidence on a scale from 1 to 4 (1=could, 2=probably could, $3=$ probably could not, $4=$ could not). The expense shock questions were written identically to prior studies in an effort to build on the existing literature (Lusardi, 2011). While the language across the income and expense conditions was not perfectly parallel, we aimed to create neutrally worded scenarios that were as similar as possible.

Participants were subsequently asked what methods they would use to handle a financial shock by answering the question: "If you were to face this unexpected $\$ 400(\$ 2,000)$ shortage (expense) in the next month, what methods would you use to (attempt to) handle this situation?" This question and the response options were also based on prior literature, with the response options most closely resembling those used by the Federal Reserve (Lusardi et al., 2011; 
Larrimore et al., 2017). Participants could select one or multiple of the following choices for coping with the financial shock: 1) With cash or money from my checking account, 2) With money from my savings account, 3) Put it on a credit card, and pay it off in full at the next statement, 4) Put it on my credit card and pay it off over time, 5) By borrowing from a friend or family member, 6) Using a payday loan, deposit advance or overdraft, 7) By selling something, and 8) Other. Finally, participants completed a series of demographic questions on their income range, age, race, and level of education.

\section{Results and Discussion}

We found that participants reported being less likely to handle an income shock than an expense shock, and this held for both the small dollar $(\$ 400)$ and large dollar $(\$ 2,000)$ conditions $\left[F(3,2003)=51.41, p<.001, \eta^{2}{ }^{2}=.02\right]$. In line with previous research(Lin et al., 2016; Lusardi et al., 2011), we coded those who answered that they either (1) could or (2) probably could as being able to handle the shock and those who answered that they either (3) probably could not or (4) could not as being unable to handle the shock (Figure 1). While $63 \%$ of participants indicated they would be able to handle an expense shock of $\$ 2,000$, only $47 \%$ of participants indicated they would be able to cover an income shortage of $\$ 2,000\left[X^{2}(1,995)=24.66, p<.001\right]$. This was also observed for the group exposed to the $\$ 400$ shock: $79 \%$ reported they would be able to handle the smaller expense shock, and $68 \%$ reported they would be able to handle the smaller income shock $\left[X^{2}(1,1,009)=17.05, p<.001\right]$. Participants who were asked about a $\$ 2,000$ income shock reported being less likely to handle the unexpected event than those who were asked about a $\$ 400$ income shock $\left[X^{2}(1,998)=42.51, p<.001\right]$, as were those who were asked about a $\$ 2,000$ versus $\$ 400$ expense shock $\left[X^{2}(1,1,006)=32.33, p<.001\right]$. 


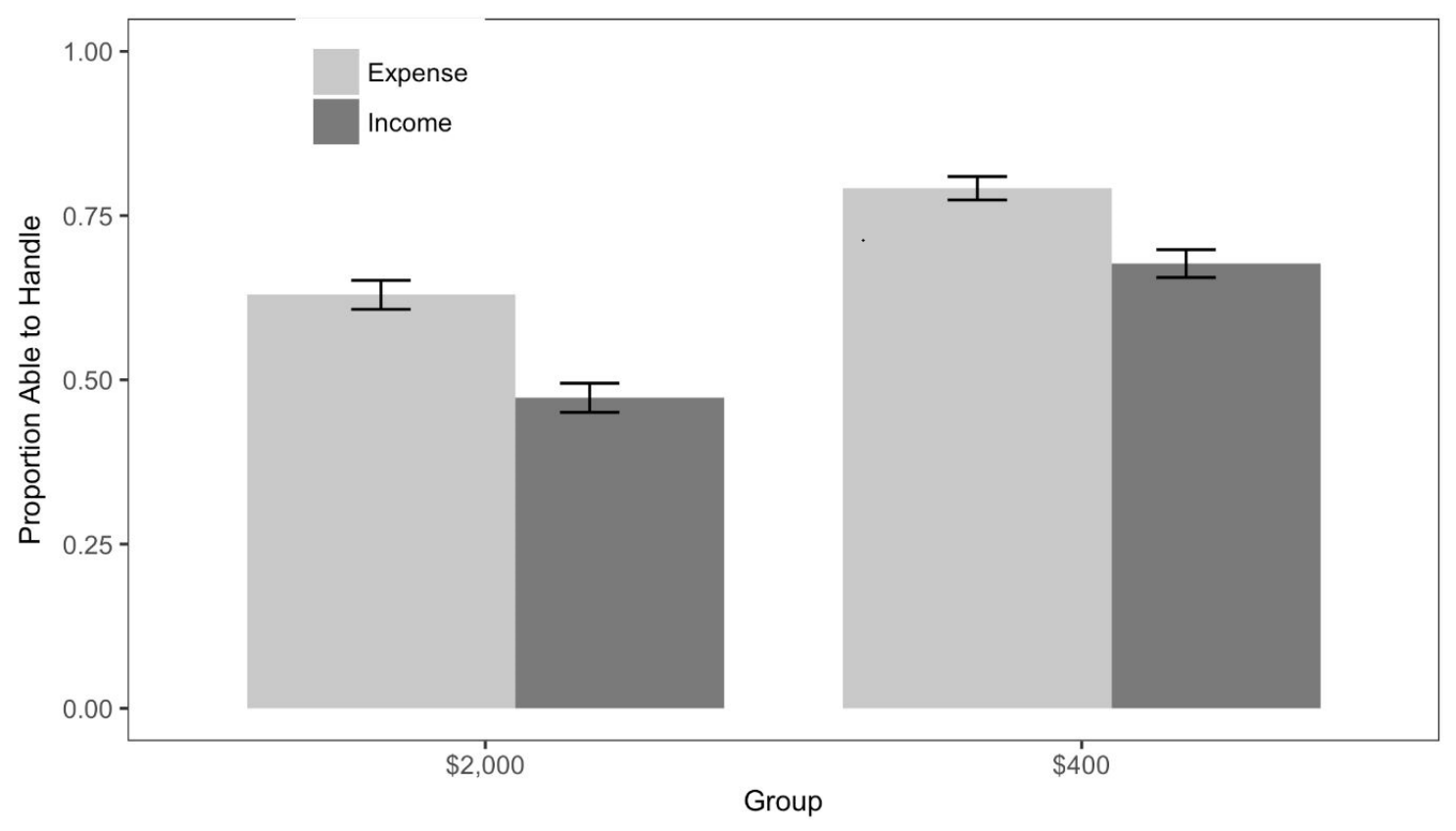

Figure 1. Ability to handle shock by type and size in Experiment 1. Proportion of participants reporting could, or probably could, handle an expense versus an income shock for large $(\$ 2,000)$ and small (\$400) shocks. Error bars indicate $\pm 1 \mathrm{SE}$.

To understand how a participant's income affects their ability to handle financial shocks, we examined the result of our experiment by household income groups. Our survey allowed respondents to pick from one of five possible options for their household income. These bands started at zero and were $\$ 25,000$ wide, with the last option being $\$ 100,000$ or more. While there are not equal shares in each income band, the conditional distributions of participants across the five income quintiles were equal across four conditions. In all the income subgroups, for both the $\$ 400$ and $\$ 2,000$ shocks, participants were more likely to report being able to handle the expense shock than the income shock (Fig.2, Table 2). However, these differences were not significantly different for those in the lowest income bracket, or when comparing the small shock (\$400) in the group with the highest reported income. To illustrate this point further, for each of the four conditions, those in households making less than $\$ 25,000$ were less likely to be able to cope with 
a shock than those making from $\$ 25,000$ up to $\$ 50,000$, and individuals in this latter category were less likely to be able to cope than those making $\$ 50,000$ or more.

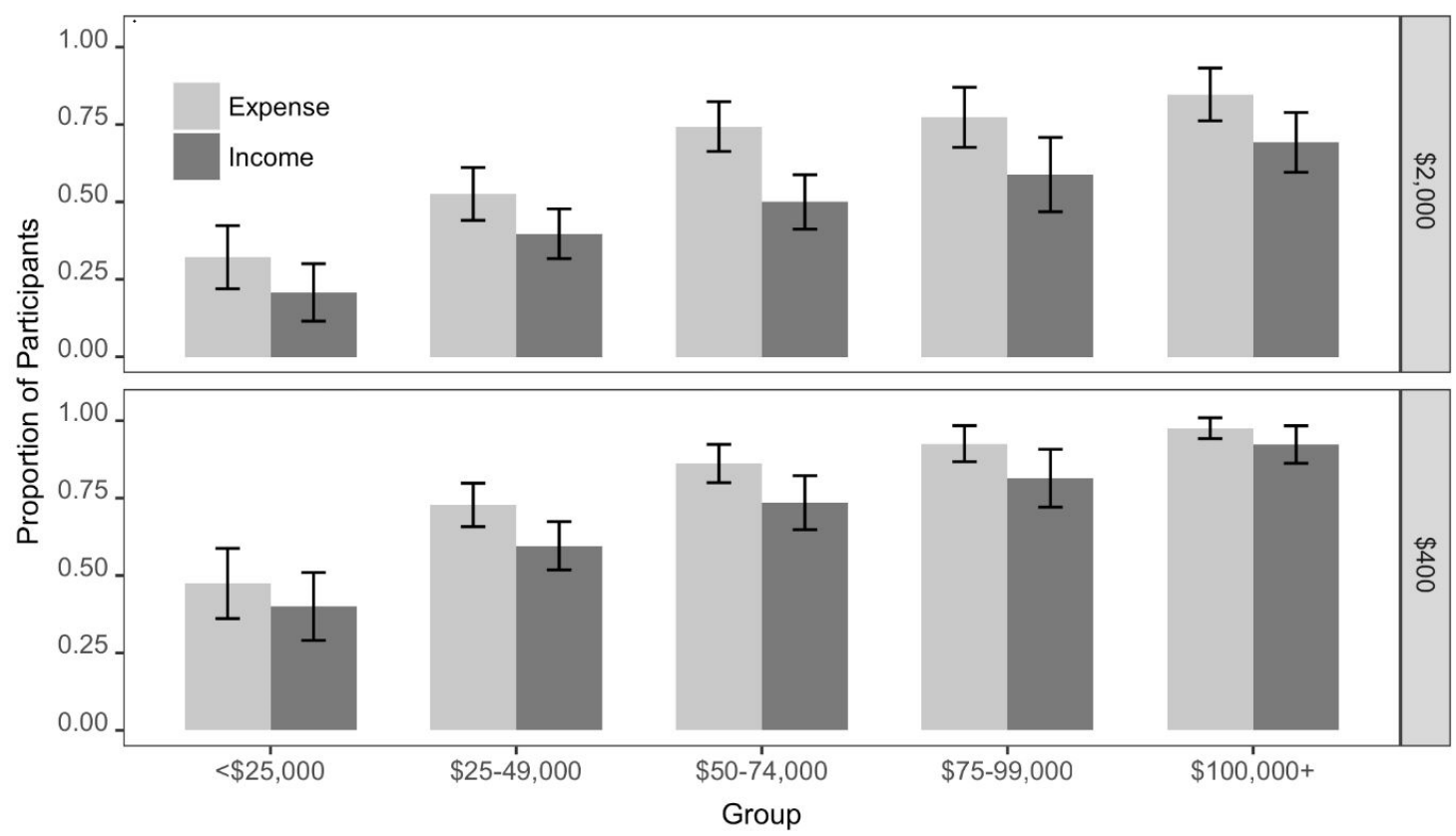

Figure 2. Ability to handle shock by type and size split by income in Experiment 1. Proportion of participants reporting could, or probably could, handle an expense versus an income shock for large $(\$ 2,000)$ and small $(\$ 400)$ shocks separated by income groups. Error bars indicate $\pm 1 \mathrm{SE}$.

Table 2. Percent of participants that could or probably could handle a shock, breakdown by income groups in Experiment 1.

\begin{tabular}{lcccccc} 
& $\begin{array}{l}\text { All income } \\
\text { groups }\end{array}$ & $<\$ 25 \mathrm{~K}$ & $\$ 25-49 \mathrm{~K}$ & $\$ 50-74 \mathrm{~K}$ & $\$ 75-99 \mathrm{~K}$ & $\$ 100+\mathrm{K}$ \\
\hline Expense $\$ 2,000$ & 62.94 & 32.14 & 52.59 & 74.36 & 77.33 & 84.72 \\
Income $\$ 2,000$ & 47.27 & 20.78 & 39.73 & 50.00 & 58.82 & 69.23 \\
p-value & $<0.001$ & 0.10 & 0.03 & $<0.001$ & 0.02 & 0.02 \\
& & & & & & \\
Expense $\$ 400$ & 79.16 & 47.44 & 72.78 & 86.18 & 92.59 & 97.59 \\
Income $\$ 400$ & 67.70 & 40.00 & 59.62 & 73.53 & 81.43 & 92.31 \\
p-value & $<0.001$ & 0.345 & 0.01 & 0.02 & 0.04 & 0.12 \\
\hline
\end{tabular}

Finally, we compared the number of methods used to address an expense or income shock of varying sizes, shown in Figure 3. Of the participants considering a small income shock, $59 \%$ reported the need to use more than one method to cope with the shock, compared to $47 \%$ of 
individuals considering a small expense shock $\left[X^{2}(1,1,009)=12.73, p<.001\right]$. By contrast, there was no significant difference between the share of participants requiring multiple methods to handle income and expense shocks for the larger monetary amount $\left[X^{2}(1,995)=1.07, p=.30\right]$. This finding suggests that the fungibility of money may be violated based not just on the type of shock, but also based on the shock size. The significant difference in the small monetary amounts, but not the large, was driven by a lower proportion of participants who could handle the small expense shock by using only one method (47.4\%). In contrast, the other three groups had similar proportions of people resorting to multiple methods, $58.6 \%, 60.0 \%$, and $56.7 \%$. The evidence that the small expense shock had the lowest proportion of people using multiple methods is consistent with the evidence from Figure 1, which shows that respondents assigned to this condition reported a greater propensity to handle the shock. The lack of a significant difference between the two large shocks suggests that it is difficult to handle a $\$ 2,000$ shock, regardless of whether the source of the shock is an income shortage or an unexpected expense.

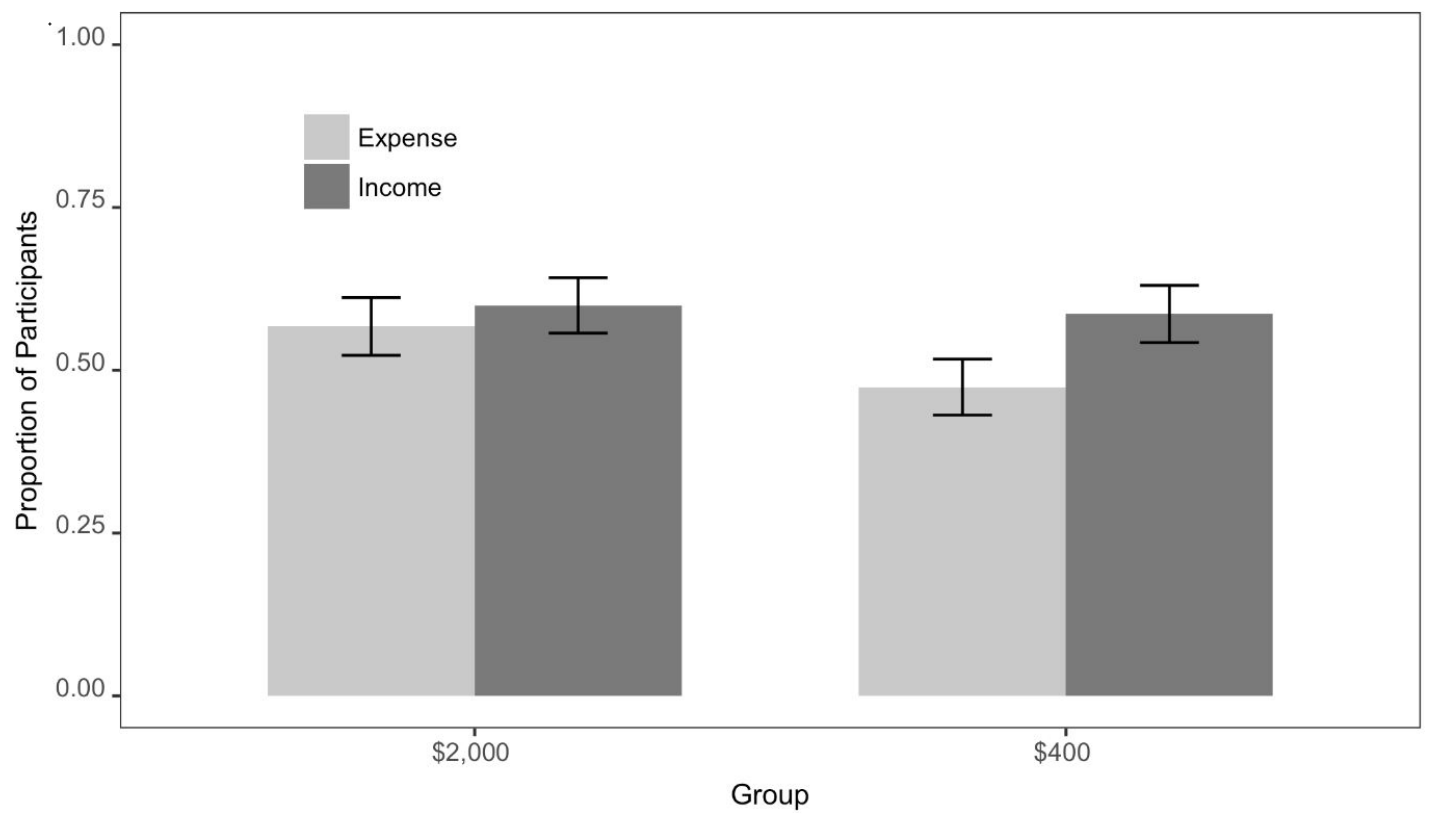

Figure 3. Multiple coping methods by shock type and size in Experiment 1. Proportion of Participants reporting the need to use more than one method to handle an expense versus an income shock for large $(\$ 2,000)$ and small $(\$ 400)$ amounts. Error bars indicate $\pm 1 \mathrm{SE}$. 


\section{Experiment 2}

This experiment aimed to replicate and extend the behavioral responses from Experiment 1 and also to explore potential underlying mechanisms of loss perception in response to income and expense shocks.

\section{Participants}

This experiment is pre-registered on osf.io/z864d. We conducted an online survey which recruited 507 participants from MTurk. A total of 79 participants were excluded using the preregistered exclusion criteria: survey completion in less than one minute or greater than 15 minutes $(N=27)$; and qualitative responses with less than five words or were viewed as nonsensical by the coders $(N=52)$. Of the remaining 428 participants, the mean age was 39.85 years $(S D=12.50)$ and was equally split between female participants $(50.6 \%)$ and male participants $(48.5 \%)$. The sample size was greater than the minimum size $(n=400)$ required to detect an effect size of $d=0.28$ with power $=0.80$, and alpha $=0.05$. Participants' median annual income was $\$ 45,000$. In terms of racial diversity, our sample was slightly biased whereby $69.9 \%$ were White; $14.3 \%$ were Asian; 8.4\% were Black/African American; and 3.5\% were Hispanic/Latino.

\section{Stimuli and Procedure}

Participants $(N=428)$ were randomly assigned to one of four conditions as in Experiment 1: a small income shock $(\$ 400, N=109)$, a large income shock $(\$ 2,000, N=107)$, a small expense shock $(\$ 400, N=102)$ or a large expense shock $(\$ 2,000, N=110)$. In each condition, participants first read a financial shock scenario, and answered questions that assessed four dependent variables: how difficult it was to cope with the shock, the magnitude of impact on their daily 
lives, their perception of loss, and their willingness to contribute to emergency savings (see Supplementary Material for the full survey). Specifically, participants rated how difficult it would be to cope with the scenario ( $1=\mathrm{I}$ will not have any difficulty, $7=\mathrm{I}$ will have significant difficulties), how much impact it would have on their daily life (1=It will have no negative impact whatsoever, 7=It will have significant negative impacts), how much they agreed with the statement that the shock felt like a pure loss to them (1=completely disagree, $4=$ neutral, $7=$ completely agree), and how willing they would be to save money for future unexpected shocks ( $1=$ not willing at all, $4=$ neutral, $7=$ very willing). There were three statements assessing perception of loss and we calculated an average score as a measure of loss perception. We also used three statements assessing willingness to save to calculate an average score. Participants were then asked how much money they would be able to save on a monthly basis for financial emergencies, and provided a long answer text box to describe how their lifestyle would change and whether it would require them to make sacrifices that have long-term consequences. The survey concluded by collecting the participants' demographics on age, gender, annual income, and education level.

\section{Results and Discussion}

Pre-registered Analyses

We conducted a 2x2 ANOVA (shock type: income vs. expense x shock size: \$2,000 vs. $\$ 400$ ) on each of the four measures (Table 3). There was a significant main effect of shock type on three DVs: Income shocks were perceived as more difficult to cope with $[F(1,424)=14.25$, $\left.p<.001, \eta^{2}{ }^{2}=.03\right]$, had a larger impact on daily life $\left[F(1,424)=4.77, p=.03, \eta_{p}^{2}=.01\right]$, and were perceived as more of a loss $\left[F(1,424)=5.41, p=.02, \eta^{2}=.01\right]$ than expense shocks of the same amount (Figure 4). However, contrary to our hypothesis participants were more willing to save 
for expense shocks than income shocks $\left[F(1,424)=4.08, p=.04, \eta^{2}{ }^{2}=.01\right]$. Additionally, large shocks were perceived as more difficult to cope with $\left[F(1,424)=12.34, p<.001, \eta^{2} p^{=.03}\right]$, had a larger impact on daily life $\left[\mathrm{F}(1,424)=21.89, p<.001, \eta^{2}=.05\right]$ and were perceived as more of a loss $\left[F(1,424)=18.85, p<.001, \eta_{p}^{2}=.04\right]$ than small shocks. Thus, the results replicated findings from Experiment 1 and demonstrated that income shocks were consistently perceived as more difficult to manage than expense shocks of the same amount.

A

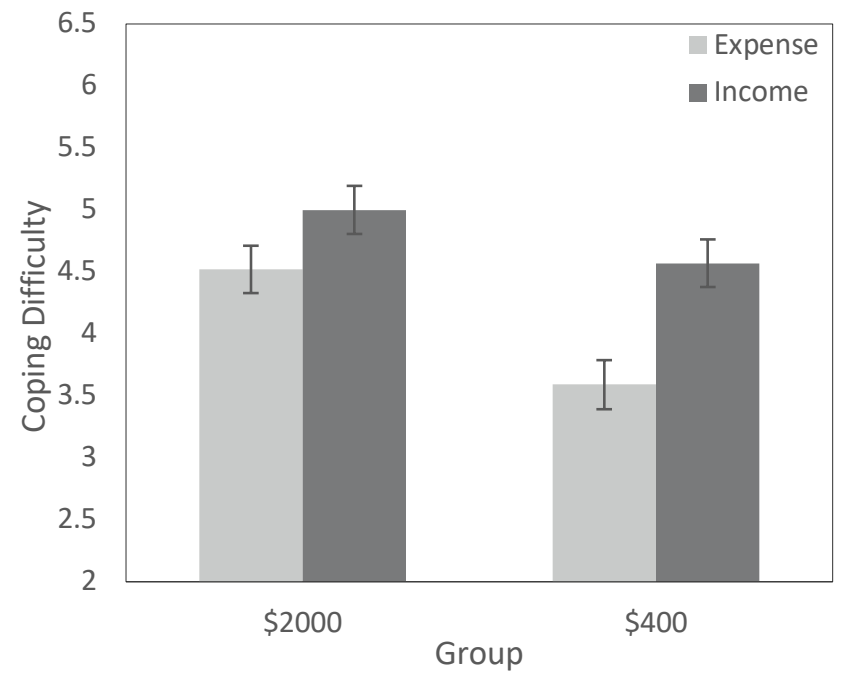

$\mathrm{C}$

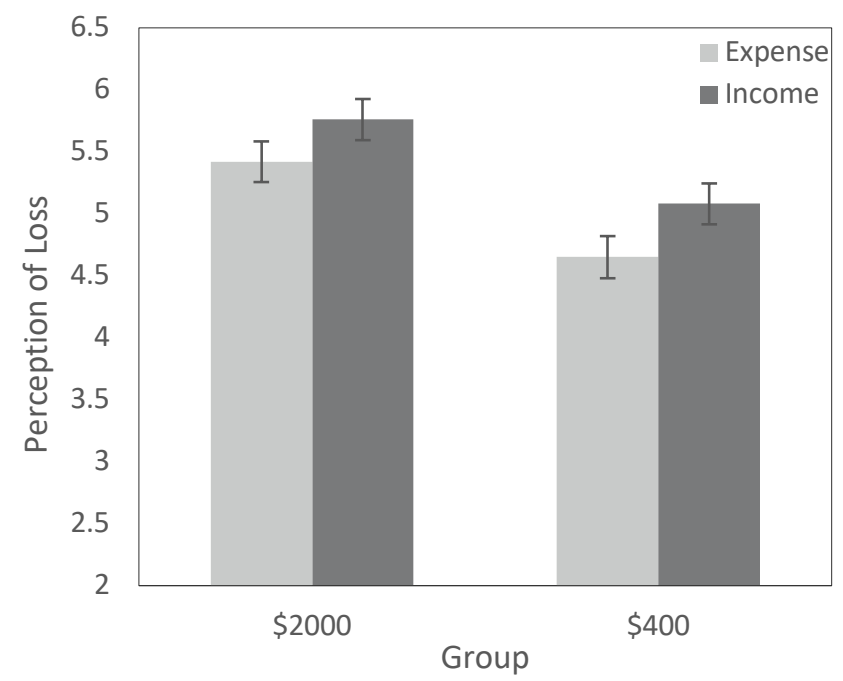

B

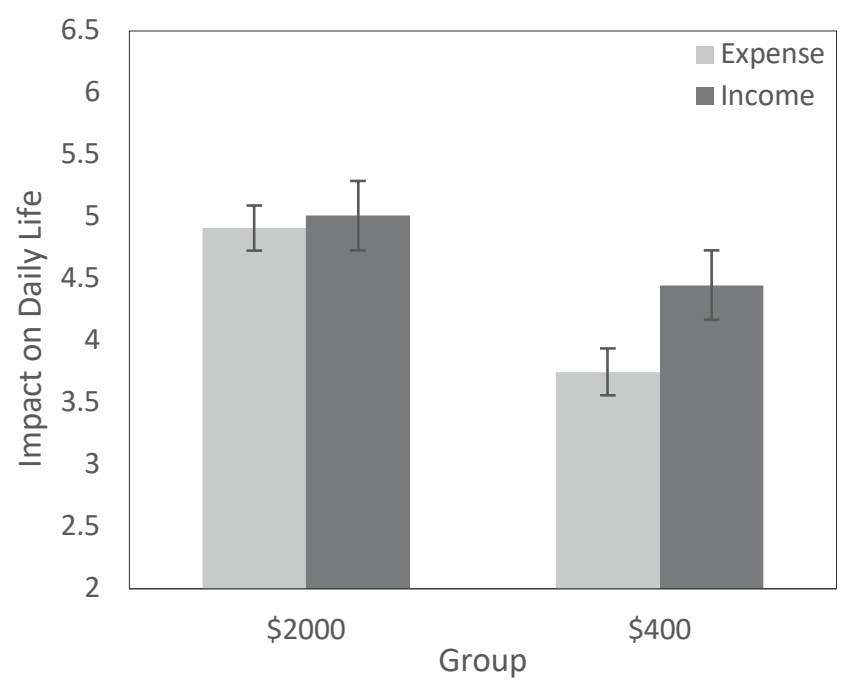

$\mathrm{D}$

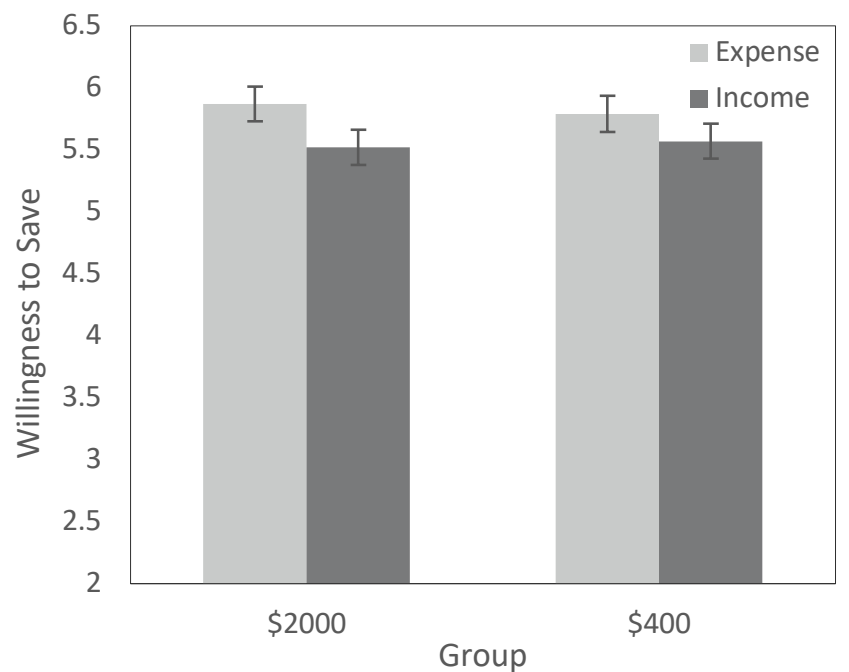

Figure 4. Coping difficulty (A), impact on daily life (B), perception of loss (C), and willingness to save (D) by shock type and shock size in Experiment 2. Error bars indicate \pm 1 SE. 
Table 3. Two-way ANOVA results on coping difficulty, impact on life, loss perception and willingness to save in Experiment 2.

\begin{tabular}{lccc}
\hline Measures & $F$ & $p$-value & $\eta^{2} p$ \\
\hline Coping Difficulty & & & \\
Shock Size & 12.34 & $<.001$ & 0.03 \\
Shock Type & 14.25 & $<.001$ & 0.03 \\
Shock Size x Shock Type & 1.66 & 0.20 & 0.00 \\
\hline Impact on Life & & & \\
Shock Size & 21.89 & $<.001$ & 0.05 \\
Shock Type & 4.77 & 0.03 & 0.01 \\
Shock Size x Shock Type & 2.69 & 0.10 & 0.01 \\
\hline Soss Perception & & & \\
$\quad$ Shock Size & 18.85 & $<.001$ & 0.04 \\
Shock Type & 5.41 & 0.02 & 0.01 \\
Shock Size x Shock Type & 0.08 & 0.77 & 0.00 \\
\hline Shock Size & & & \\
Shock Type & 0.01 & 0.91 & 0.00 \\
Shock Size x Shock Type & 0.19 & 0.66 & 0.00 \\
\hline
\end{tabular}

\section{Exploratory Analyses}

To explore whether loss perception of the shock mediated the relationship between shock type and behavioral responses, we conducted a mediation analysis which showed that perception of loss mediated the relationship between shock type and the impact on daily life $[\beta=0.378$, $t=2.00, p=.045]$, and with the inclusion of the mediating variable (loss perception), the impact of shock type on impact on life was not significant $[\beta=0.159, t=0.96, p=.34]$. In addition, perception of loss partially mediated the relationship between shock type and coping difficulty $[\beta=0.712$, $t=3.63, p<.01]$. In this case, with the inclusion of the mediating variable (loss perception), the impact of shock type on coping difficulty was still significant $[\beta=0.486, t=2.91, p<.01]$. Finally, perception of loss did not mediate the relationship between shock type and willingness to save. 
Moreover, we examined the roles of covariates (age, gender, personal annual income, political orientation) in the relationship between shock type and behavioral responses (see Table S2). To do so, we conducted an ANCOVA on each measure and found that after controlling for the covariates, all the main effects in pre-registered analyses were still significant, except for willingness to save. This suggests that the earlier effect of income shocks observed on willingness to save was likely driven by covariates. In addition, gender and personal annual income were significant for coping difficulty $\left(\left[F(1,420)=12.73, p<.001, \eta^{2}{ }^{2}=.03\right]\right.$ for gender; $\left[F(1,420)=42.79, p<.001, \eta^{2}=.09\right]$ for annual income $)$ and for impact on life $([F(1,420)=13.23$, $\left.p<.001, \eta_{p}^{2}=.03\right]$ for gender; $\left[F(1,420)=46.75, p<.001, \eta_{p}^{2}=.10\right]$ for annual income). For perception of loss, only personal annual income was significant $[F(1,420)=22.47, p<.001$, $\left.\eta_{p}^{2}=.05\right]$. No other covariates were significant.

A final exploratory analysis was done on how much participants were willing to save for future financial emergencies. Interestingly, we found a significant two-way interaction between shock type and shock size $\left[\mathrm{F}(1,401)=6.37, p=.01, \eta^{2}=.02\right]$, where participants were willing to save more money for future emergencies after encountering a $\$ 2,000$ income shock than a $\$ 400$ income shock $[t(201)=2.489, p=.01, d=0.25]$, but not for expense shocks $[t(193)=0.768, p=.44$, $d=0.02]$. This result suggests that larger income shocks trigger greater preparation for future financial emergencies than larger expense shocks.

\section{Experiment 3}

Experiments 1 and 2 suggest that income shocks place a greater psychological toll than expense shocks of the same amount. As a behavioral intervention to mitigate the effects, we administered a self-affirmation intervention before participants encountered the income or expense shock to see whether the intervention could mitigate negative behavioral consequences. 


\section{Participants}

The experiment is pre-registered on osf.io/5c943. Similar to Experiment 2, we conducted an online survey that recruited 1044 participants on MTurk. A total of 176 participants were excluded based on pre-registered exclusion criteria: incomplete survey answers $(N=24)$; survey completion in less than one minute or greater than 30 minutes $(N=48)$; and qualitative responses that had less than five words or were viewed as nonsensical by the coders $(\mathrm{N}=104)$. The final sample size was $N=868$, with a mean age of 33.7 years $(\mathrm{SD}=11.10)$ whereby $48.3 \%$ of participants were female. This sample size exceeded the minimum size $(n=800)$ required to detect an effect size of 0.10 with power $=0.80$, and alpha $=0.05$. Participants' median annual income was $\$ 45,000$ and $70.8 \%$ of our sample were White; $14.3 \%$ were Asian; $12.4 \%$ were Hispanic/Latino and 9.7\% were Black/African American.

\section{Stimuli and Procedure}

Participants $(N=868)$ were randomly assigned to one of eight conditions: 2 (affirmed vs. control) x 2 (shock type: income vs. expense) x 2 (shock size: large vs. small). In the affirmed conditions, participants were first instructed to describe a personal experience that made them feel successful and proud by typing their description in a text box. In the control conditions, participants were first instructed to describe their daily meal routine by typing their description in a text box (see Supplementary Material for the instructions). The same instructions were used in Hall et al. (2014) that examined the impact of self-affirmation on cognitive function and behavioral interests in benefit programs. After writing out the description, participants responded to two questions that measured how they were feeling about themselves at the moment: "How do you feel about yourself right now?" (1=not positive at all, 4=neutral, 7=very positive); and "How confident are you that you will be able to handle problems arising in the future?" (1=not 
confident at all, 4=neutral, 7=very confident). Afterwards, participants were randomly assigned to the four conditions and completed the study as in Experiment 2.

\section{Results and Discussion}

Pre-registered Analyses

As a manipulation check, we found that participants in the self-affirmation condition felt significantly more positive about themselves $\left[F(1,866)=16.00, p<.001, \eta^{2}=0.02\right]$ and had significantly higher self-confidence in handling future problems $[F(1,866)=13.68, p<.001$, $\left.\eta^{2}=0.02\right]$ than those in the control condition. This suggests that self-affirmation intervention increased self-positivity and self-confidence.

A three-way ANOVA (intervention type: affirmed vs. control x shock type: income vs. expense vs. shock size: large vs. small) revealed that self-affirmation significantly reduced coping difficulty $\left[F(1,866)=5.32, p=.02, \eta^{2} p=.01\right]$ and perceived loss $[F(1,866)=4.79, p=.03$, $\left.\eta^{2}=.01\right]$, but had no effect on impact on life $\left[F(1,866)=2.23, p=.14, \eta^{2} p=.00\right]$ or willingness to save $\left[F(1,866)=0.47, p=.49, \eta^{2} p^{=}=00\right]$ (Table 4, Figure 5). This suggests that self-affirmation mitigated some negative effects of financial shocks, although with limits in promoting savings.

As in Experiment 2, income shocks were consistently perceived as more difficult to cope with $\left[F(1,866)=26.42, p<.01, \eta^{2} p=.03\right]$, had a larger impact on life $[F(1,866)=13.90, p<.001$, $\left.\eta^{2}=.02\right]$ and were perceived as more of a loss $\left[F(1,866)=9.80, p<.01, \eta^{2}{ }^{2}=.01\right]$ than expense shocks of the same amount. However, this time income shocks did not have a significant effect on willingness to save $\left[F(1,866)=1.30, p=.26, \eta^{2}=.00\right]$. As before, larger shocks were perceived as more difficult to cope with $\left[F(1,866)=14.17, p<.001, \eta^{2}=.02\right]$ and more impactful on daily life $\left[F(1,866)=14.17, p<.001, \eta^{2}{ }^{2}=.02\right]$ than smaller shocks. No other main effects were significant. These results largely replicated the findings from Experiment 2. 

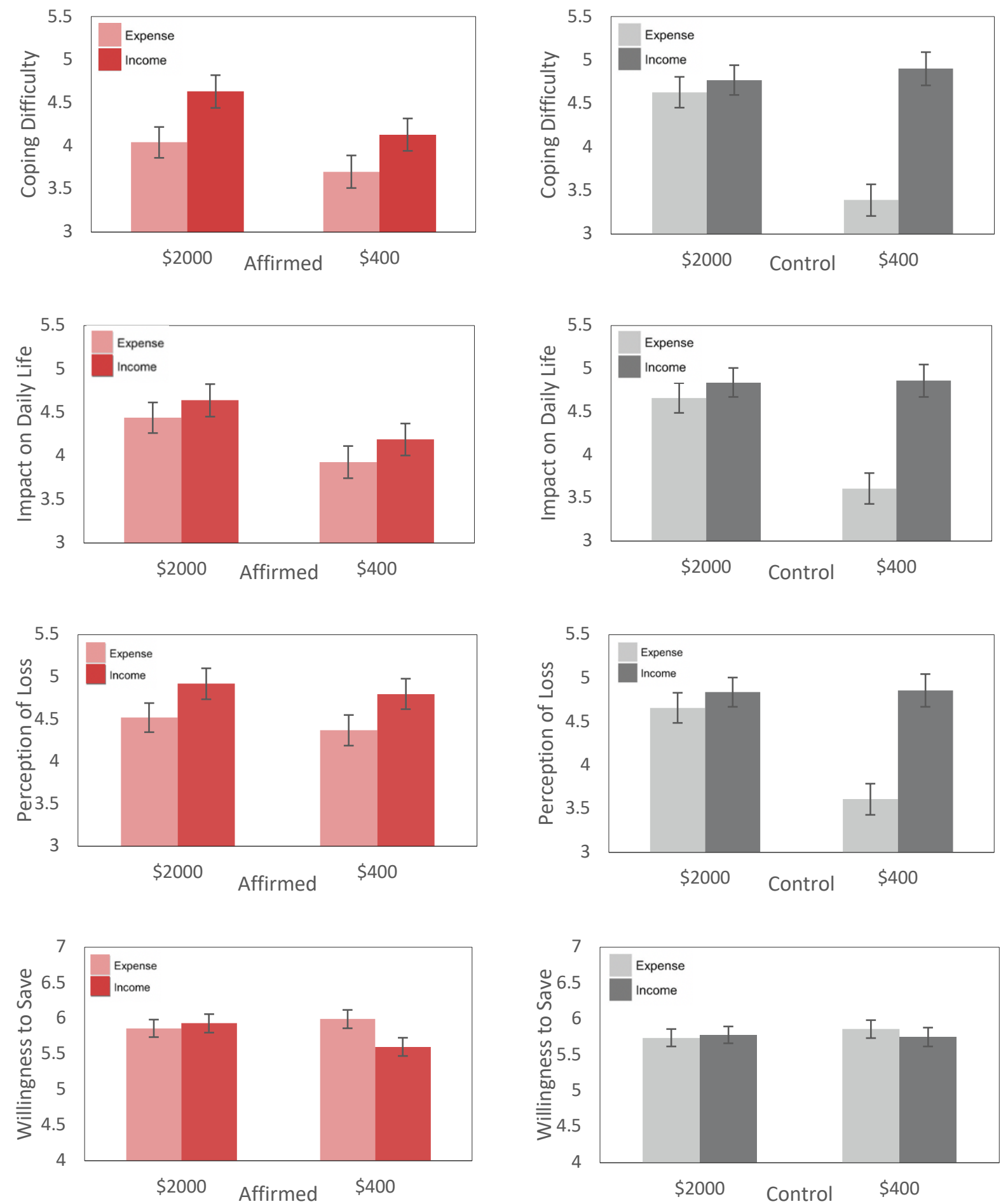

Figure 5. Coping difficulty, impact on daily life, perception of loss, and willingness to save for affirmed condition and control condition by shock type and shock size in Experiment 3. Error bars indicate $\pm 1 \mathrm{SE}$. 
Table 4. Three-way ANOVA results on coping difficulty, impact on life, loss perception and willingness to save in Experiment 3.

\begin{tabular}{|c|c|c|c|}
\hline Measures & $F$ & $p$-value & $\eta^{2} p$ \\
\hline \multicolumn{4}{|l|}{ Coping Difficulty } \\
\hline Intervention Type & 5.33 & 0.02 & 0.01 \\
\hline Shock Type & 26.42 & $<.001$ & 0.03 \\
\hline Shock Size & 14.17 & $<.001$ & 0.02 \\
\hline Intervention Type x Shock Type & 1.43 & 0.23 & 0.00 \\
\hline Intervention Type x Shock Size & 0.26 & 0.51 & 0.00 \\
\hline Shock Type x Shock Size & 5.35 & 0.02 & 0.01 \\
\hline Intervention Type x Shock Type x Shock Size & 8.87 & $<.01$ & 0.01 \\
\hline \multicolumn{4}{|l|}{ Impact on Life } \\
\hline Intervention Type & 2.23 & 0.14 & 0.00 \\
\hline Shock Type & 13.90 & $<.001$ & 0.02 \\
\hline Shock Size & 15.24 & $<.001$ & 0.02 \\
\hline Intervention Type x Shock Type & 3.61 & 0.06 & 0.00 \\
\hline Intervention Type x Shock Size & 0.02 & 0.89 & 0.00 \\
\hline Shock Type x Shock Size & 4.88 & 0.03 & 0.01 \\
\hline Intervention Type x Shock Type x Shock Size & 3.97 & 0.05 & 0.01 \\
\hline \multicolumn{4}{|l|}{ Loss Perception } \\
\hline Intervention Type & 4.79 & 0.03 & 0.01 \\
\hline Shock Type & 9.8 & $<.01$ & 0.01 \\
\hline Shock Size & 3.42 & 0.07 & 0.00 \\
\hline Intervention Type x Shock Type & 0.04 & 0.84 & 0.00 \\
\hline Intervention Type x Shock Size & 0.58 & 0.45 & 0.00 \\
\hline Shock Type x Shock Size & 2.90 & 0.09 & 0.01 \\
\hline Intervention Type x Shock Type x Shock Size & 2.56 & 0.11 & 0.00 \\
\hline \multicolumn{4}{|l|}{ Willingness to Save } \\
\hline Intervention Type & 0.47 & 0.49 & 0.00 \\
\hline Shock Type & 1.30 & 0.26 & 0.00 \\
\hline Shock Size & 0.10 & 0.76 & 0.00 \\
\hline Intervention Type x Shock Type & 0.46 & 0.50 & 0.00 \\
\hline Intervention Type x Shock Size & 0.70 & 0.40 & 0.00 \\
\hline Shock Type x Shock Size & 2.96 & 0.09 & 0.00 \\
\hline Intervention Type x Shock Type x Shock Size & 0.81 & 0.37 & 0.00 \\
\hline
\end{tabular}

\section{Exploratory Analyses}

The three-way ANOVA also showed a significant three-way interaction for coping difficulty $\left[F(1,866)=8.87, p<.01, \eta_{p}^{2}=0.01\right]$, and a marginal three-way interaction for impact on daily life $\left[F(1,866)=3.97, p=.05, \eta^{2} p=0.01\right]$. Delving into the interactions, we found that self- 
affirmation significantly reduced coping difficulty for income shocks $[t(428)=2.56, p=.01$, $d=0.25]$, but not for expense shocks. Self-affirmation also reduced perceived impact on daily life for income shocks $[t(428)=2.42, p=.02, d=0.23]$, but not for expense shocks. These results suggest that self-affirmation had a larger impact in alleviating the negative behavioral responses resulting from income shocks than from expense shocks.

We further completed a three-way ANCOVA controlling for covariates of age, gender, personal annual income, and political orientation (see Table S3). This analysis showed that after controlling for the covariates, the significant main effects in pre-registered analyses still remained significant. In addition, personal annual income was a significant covariate for coping difficulty $\left[F(1,858)=85.61, p<.001, \eta^{2}=0.09\right]$, impact on life $[F(1,858)=102.05, p<.001$, $\left.\eta^{2}{ }^{2}=0.11\right]$, and perception of loss $\left[F(1,858)=29.70, p<.001, \eta^{2}{ }^{2}=0.03\right]$. Political orientation was also a significant covariate for willingness to save $\left[F(1,858)=7.38, p=.01, \eta^{2} p^{=0.01]}\right.$. No other covariates were significant.

A final exploratory analysis examined whether self-affirmation influenced the amount of money participants were willing to save for future financial emergencies. Self-affirmation unfortunately had no impact on savings amount $\left[\mathrm{F}(1,829)=0.16, p=.69, \eta^{2}=.00\right]$. This is consistent with the pre-registered analysis showing the lack of impact of self-affirmation on willingness to save. However, as in Experiment 2, there was a significant two-way interaction between shock type and shock size $\left[\mathrm{F}(1,829)=4.74, p=.03, \eta^{2}=.006\right]$, where participants were willing to save more money for future financial emergencies after encountering a $\$ 2,000$ income shock than a $\$ 400$ income shock, but this was not the case for expense shocks. This again suggests that larger income shocks elicit greater preparation for future financial emergencies than larger expense shocks. 


\section{General Discussion}

When policymakers and other advocates consider the short-term and long-term implications of financial hardships on financial stability, they may be making implicit assumptions about the type of hardship experienced. These assumptions may influence the types of financial products and policy tools proposed to help people weather financial challenges. To date, the literature has largely treated all types of financial shocks as equal, or simply considered expense shocks as the most frequent, relevant, or challenging (Lusardi et al., 2011; Larrimore et al., 2017; Lin et al. 2016). The literature on mental accounting and budgeting, complemented by this study, suggests that this ought not to be the case (Thaler, 1999; Heath and Soll, 1996; Barberis and Huang, 2001). Our findings suggest that income shocks place a greater psychological toll than expense shocks of the same amount, and self-affirmation can be an effective tool to mitigate the negative effects of the shocks. The current findings suggest that people may use different mental accounting strategies to frame and cope with income and expense shocks. The new insights from this work can benefit researchers and policymakers who aim to improve the financial resilience of individuals to weather financial challenges. A nuanced understanding of how families cope with financial shocks will allow for more informed and effective interventions to address them.

All three experiments demonstrated that people are less able to cover a shock in their income relative to an unexpected expense of equal size. This finding provides the first evidence that the psychological transaction costs of an income shock are greater than those of an expense shock. This work uses insights from the psychological literature to build on the existing research examining emergency expenses and provides critical nuance to this conversation. The mental accounting categories that people use to track their income and expenses cannot be ignored when 
trying to understand how they respond to difficult financial situations. As the circumstances that lead to expense or income shocks will vary in critical ways, so too do the differences in perception of available coping mechanisms for that particular shock.

The differential behavioral responses elicited by income vs. expense shocks suggest that the source of the shock can trigger different framing, with income shocks framed broadly and expense shock framed narrowly. The finding that income shocks are more difficult to cope with and are perceived more as a loss than expense shocks suggests that income shocks are represented as a drop in wealth, requiring more mental accounts to draw from to cope. Indeed, participants reported the need to resort to more options of coping for income shocks than expense shocks in Experiment 1, which supports the broad framing of income shocks. In Experiment 2, income shocks were perceived as a greater loss than expense shocks of the same amount, and this perception mediated the impact of income shocks on coping difficulty. This may be due to the fact that income shortfalls are less attributable to a specific cause while expense shocks are often associated with specific reasons. The greater perceived loss of income shocks also suggests that while a one-time pay cut is felt as a pure loss, an expense shock may be perceived as both a loss and a gain (e.g., losing $\$ 2,000$ to gain a functional car).

In terms of emergency savings, income shocks had little impact on the rated willingness to save, but larger income shocks elicited a greater savings amount for future financial emergencies than larger expense shocks did in Experiments 2 and 3. Taken together, these results support our general hypothesis that income shocks place a greater psychological toll than expense shocks and require more coping resources.

In Experiment 3, self-affirmation showed some efficacy in mitigating the negative psychological effects of financial shocks, with a greater efficacy for income shocks than expense 
shocks. Self-affirmation reduced coping difficulty and perceived loss from shocks, but had no impact on willingness to save for future financial emergencies. These results partially supported our predictions, but also revealed the limitations of the self-affirmation intervention in promoting emergency savings. The more positive feeling about oneself and increased self-confidence in handling future problems may have backfired in this case as the boost in confidence may have attenuated the perceived severity of future problems and minimized the need to save. The result also calls for caution in using self-affirmation to increase financial resilience because selfaffirmation may be a double-edged sword: while it increases self-confidence and reduces perceived coping difficulty, it may not instigate meaningful actions to prepare for future financial emergencies. More research is needed to improve the efficacy of self-affirmation in this regard.

The current findings have crucial implications for both researchers and policymakers who aim to improve the economic security of working individuals. Beyond the increased psychological transaction costs associated with income shocks, volatility may have downstream economic costs that affect workers' long-term financial security, such as increased debt or instability in basic expenses like housing and food. The insights from this study can be used to improve the understanding of consumption habits and household finance more broadly. Additionally, they can be used to inform public policy options designed to help mitigate economic emergencies, such as income smoothing policies like paid sick leave, secure scheduling laws, or guaranteed minimum hours. This work can also inform how different policies and programs should be communicated, especially to those in low-wage positions.

Given the apparent distinction in perception, future research could delve into the nuances of income and expense shocks even further. Research could investigate whether people view financial shocks as sporadic, or indicative of a regular pattern and how these perceptions alter 
their coping behavior. For example, the impact of an income shock that comes from a seasonal change in hours worked may be treated differently than an income shock that is the result of being laid off unexpectedly. Further consideration should also be given to how existing policies might be leveraged to encourage low-income households to develop a savings buffer. Given differences in resources available to dedicate to building emergency savings, interventions targeted at low-income households can take advantage of existing policies such as the EITC. Interventions implemented around tax-time can have an impact on savings account ownership and behavior (Despard et al., 2018) particularly given that many low- and moderate-income filers underestimate their tax refund, and that refund can account for a significant portion of annual income (Hall and Romich, 2016).

A large proportion of Americans feel unequipped to handle financial challenges, and our research highlights that this problem is even more acute for unexpected shortfalls in income. Given the rise in income volatility (Dynan et al., 2012) and the findings of this study, people may be more vulnerable to dips in income compared to unexpected expenses. Our study highlights the need to promote thoughtful policies that consider the psychology of financial decision making to ultimately improve the financial outcomes of low-income households. As the United States, and the world more broadly, copes with unprecedented social and financial challenges, the need for extreme foresight in helping individuals prepare for financial emergencies has never been more evident. 


\section{Declaration of funding}

The funding for the current work is provided by UBC \& University of Washington Collaborative Research Mobility Award (\#F20-03645). The funder played no role in the design, execution, analysis and interpretation of data, or writing of the study.

\section{Competing interests declaration}

The authors declare no competing interests. 


\section{References}

American Psychological Association (2020). Stress in America ${ }^{\text {TM }}$ 2020: A National Mental Health Crisis. Retrieved from: https:/www.apa.org/news/press/releases/stress/2020/siamental-health-crisis.pdf

Artige, L., \& Cavenaile, L. (2012). A Growth Model of Global Imbalances. SSRN Electronic Journal. https://doi.org/10.2139/ssrn.2119913

Alam, K., \& Mahal, A. (2014). Economic impacts of health shocks on households in low and middle income countries: A review of the literature. Globalization and Health, 10(1), 118.

Barberis, N., \& Huang, M. (2001). Mental accounting, loss aversion, and individual stock returns. The Journal of Finance, 56(4), 1247-1292.

Berbaum, J. (2020). Survey Reveals Spending Habits During COVID-19. Highland, retrieved from: https://highlandsolutions.com/blog/survey-reveals-spending-habits-during-covid-19

Berinsky, A. J., Huber, G. A., \& Lenz, G. S. (2012). Evaluating online labor markets for experimental research: Amazon. Com’s Mechanical Turk. Political Analysis, 20(3), 351368.

Bhargava, V., \& Lown, J. M. (2006). Preparedness for financial emergencies: Evidence from the Survey of Consumer Finances. Journal of Financial Counseling and Planning, 17(2), 1726.

Bickel, W. K., Wilson, A. G., Chen, C., Koffarnus, M. N., \& Franck, C. T. (2016). Stuck in Time: Negative Income Shock Constricts the Temporal Window of Valuation Spanning the Future and the Past. PLOS ONE, 11(9). https://doi.org/10.1371/journal.pone.0163051 
Bhutta, N., \& Dettling, L. J. (2018). Money in the Bank? Assessing Families' Liquid Savings using the Survey of Consumer Finances. Board of Governors of the Federal Reserve System (US).

Cohen, G. L., \& Sherman, D. K. (2014). The Psychology of Change: Self-Affirmation and Social Psychological Intervention. Annual Review of Psychology, 65(1), 333-371. https://doi.org/10.1146/annurev-psych-010213-115137

D’Ambrosio, C., Menta, G., \& Wolff, E. N. (2019). Income and Wealth Volatility: Evidence from Italy and the US in the Past Two Decades. National Bureau of Economic Research.

Despard, M., Grinstein-Weiss, M., Deruyter, A., Guo, S., Oliphant, J. E., \& Friedline, T. (2018). Effects of a randomized tax-time savings intervention on savings account ownership among low-and moderate-income households. Journal of Financial Counseling and Planning, 29(2), 219-233.

Dynan, K., Elmendorf, D., \& Sichel, D. (2012). The evolution of household income volatility. The BE Journal of Economic Analysis \& Policy, 12(2).

Engelberg, E. (2007). The perception of self-efficacy in coping with economic risks among young adults: an application of psychological theory and research. International Journal of Consumer Studies, 31(1). https://doi.org/10.1111/j.1470-6431.2005.00494.x

Farber, H. S. (2008). Employment insecurity: The decline in worker-firm attachment in the united states.

Gadermann, A. C., Thomson, K. C., Richardson, C. G., Gagné, M., McAuliffe, C., Hirani, S., \& Jenkins, E. (2021). Examining the impacts of the COVID-19 pandemic on family mental health in Canada: findings from a national cross-sectional study. BMJ open, 11(1), e042871. 
Gjertson, L. (2016). Emergency saving and household hardship. Journal of Family and Economic Issues, 37(1), 1-17.

Hall, C. C., Zhao, J., \& Shafir, E. (2014). Self-affirmation among the poor: Cognitive and behavioral implications. Psychological Science, 25, 619-625.

Hall, C. C., \& Romich, J. L. (2016). Low-and moderate-income tax filers underestimate tax refunds: Implications for financial counseling and policy. Journal of Financial Counseling and Planning, 27(1), 36-46.

Heath, C., \& Soll, J. B. (1996). Mental budgeting and consumer decisions. Journal of Consumer Research, 23(1), 40-52.

Henly, J. R., \& Lambert, S. J. (2014). Unpredictable work timing in retail jobs: Implications for employee work-life conflict. ILR Review, 67(3), 986-1016.

Hitlin, P. (2016). Research in the crowdsourcing age: A case study. Pew Research Center. https://www.pewresearch.org/internet/2016/07/11/research-in-the-crowdsourcing-age-acase-study/

International Labour Organization (2020, September 30). ILO Monitor: COVID-19 and the world of work. Sixth edition updated estimates and analysis. International Labour Organization. Retrieved from: https://tinyurl.com/y4t22exl

Ipsos (2019). Nearly Half of Canadians (48\%) Are $\$ 200$ or Less Away from Financial Insolvency.Retrieved from: https://www.ipsos.com/en-ca/news-polls/Canadians-andBankruptcy-Oct-2019

Huff, C., \& Tingley, D. (2015). “Who are these people?” Evaluating the demographic characteristics and political preferences of MTurk survey respondents. Research \& Politics, 2(3), 1-12. 
Kahneman, D., \& Lovallo, D. (1993). Timid choices and bold forecasts: A cognitive perspective on risk taking. Management Science, 39(1), 17-31.

Kalleberg, A. L. (2011). Good jobs, bad jobs: The rise of polarized and precarious employment systems in the United States, 1970s-2000s. Russell Sage Foundation.

Karpman, M., Zuckerman, S., Gonzalez, D., \& Kenney, G. M. (2020). The COVID-19 pandemic is straining families' abilities to afford basic needs. Washington, DC: Urban Institute, 500.

Lambert, S. J., Henly, J. R., \& Kim, J. (2019). Precarious work schedules as a source of economic insecurity and institutional distrust. RSF: The Russell Sage Foundation Journal of the Social Sciences, 5(4), 218-257.

Larrimore, J., Durante, A., Park, C., \& Tranfaglia, A. (2017). Report on the economic well-being of US households in 2016 [Report for the Board of Governors of the Federal Reserve System]. Washington, DC: Board of Governors of the Federal Reserve System.

Lin, J. T., Lusardi, A., Mottola, G., Kieffer, C., \& Walsh, G. (2016). Financial Capability in the United States 2016 (pp. 1-37). FINRA Investor Education Foundation. https://www.finrafoundation.org/files/financial-capability-united-states-2016

Lin, J. T., Bumcrot, C., Ulicny, T., Mottola, G., Walsh, G., Ganem, R., ... \& Lusardi, A. (2019). The state of US financial capability: The 2018 national financial capability study. FINRA Investor Education Foundation. Retrieved from: https://www.usfinancialcapability.org/downloads/NFCS_2018_Report_Natl_Findings.pdf Lown, J. M., Kim, J., Gutter, M. S., \& Hunt, A.-T. (2014). Self-efficacy and Savings Among Middle and Low Income Households. Journal of Family and Economic Issues, 36(4), 491502. https://doi.org/10.1007/s10834-014-9419-y 
Lusardi, A., Schneider, D. J., \& Tufano, P. (2011). Financially fragile households: Evidence and implications. National Bureau of Economic Research.

Mendoza, R. U. (2009). Aggregate shocks, poor households and children. Global Social Policy, $9,55-78$.

Morduch, J., \& Schneider, R. (2017). The financial diaries: How American families cope in a world of uncertainty. Princeton University Press.

O’Curry, S., \& Strahilevitz, M. (2001). Probability and mode of acquisition effects on choices between hedonic and utilitarian options. Marketing Letters, 12(1), 37-49.

Ostrowski, J. (2021). Survey: Fewer than 4 in 10 Americans could pay a surprise $\$ 1,000$ bill from savings. Bankrate, retrieved from: https://www.bankrate.com/banking/savings/financial-security-january-2021/

Pinkus, E. (2020). CNBC|SurveyMonkey poll: "Invest in You” August 2020. Retrieved from: https://www.surveymonkey.com/curiosity/cnbc-invest-in-you-august-2020/

Roll, S. P., Taylor, S. H., \& Grinstein-Weiss, M. (2016). Financial Anxiety in Low-and Moderate-Income Households: Findings from the Household Financial Survey.

Schneider, D., \& Harknett, K. (2019). Consequences of routine work-schedule instability for worker health and well-being. American Sociological Review, 84(1), 82-114.

Sherman, D. K., \& Cohen, G. L. (2006). The Psychology of Self-defense: Self-Affirmation Theory. Advances in Experimental Social Psychology Advances in Experimental Social Psychology Volume 38, 183-242. doi:10.1016/s0065-2601(06)38004-5

Steele, C. M., \& Aronson, J. (1995). Stereotype threat and the intellectual test performance of African Americans. Journal of Personality and Social Psychology, 69(5), 797-811. 
Shin, S., Kim, H., \& Heath, C. J. (2019). Narrow Framing and Retirement Savings Decisions. Journal of Consumer Affairs, 53(3), 975-997.

Thaler, R. H. (1999). Mental accounting matters. Journal of Behavioral Decision Making, 12(3), $183-206$.

The Federal Reserve. (2019). Report on the Economic Well-Being of U.S. Households in 2018. https://www.federalreserve.gov/publications/files/2018-report-economic-well-being-ushouseholds-201905.pdf

United States Census Bureau. (2019). QuickFacts: United States. https:/www.census.gov/quickfacts/fact/table/US/PST045219

US Bureau of Labor Statistics. (2020). Table B-1. Employees on nonfarm payrolls by industry sector and selected industry detail. https://www.bls.gov/news.release/empsit.t17.htm 